\title{
Motivational, Engaged and Reflective Teaching Competences in Quality Teacher Fducation
}

DOI: 10.47050/66515314.284-295

Anna Aleksanyan

In the complex of the professional competences of a teacher, such main competences are highlighted as their motivational competences, integration in the learning environment, organisation of engaged learning, reflective and experience-based learning competences, etc. How should these competences be constructed and why are they important to modern education processes, especially teacher education? The answers to these questions can be found in the methodological concepts of Dewey, Bloom et al., Schön, etc.

All these concepts are generated by the modern theory of teaching, which is constructed by hybrid pedagogy. Hybrid pedagogy creates modern approaches in the organisation of learning processes, combined with the above-mentioned theories and modern challenges of e-learning concepts, based on the catalyst framework of the education process. In hybrid pedagogy, a wide range of blended learning activities and e-tivities is worked out, the usage of which makes possible to overcome modern challenges and get the required outcomes in the learning process. It has already been proved that the effectiveness of the application of all the above-mentioned methodological approaches and tools makes possible to motivate and engage learners in the learning process.

\section{Keywords:}

engaged learning

hybrid/blended pedagogy

reflective learning

teacher competences 


\section{Teachers' Professional Competences in Pre-Service Education at University}

In the $20^{\text {th }}$ century, new educational issues were raised related to the increase of students' self-esteem and the acquisition of knowledge by learners themselves. At the end of the $20^{\text {th }}$ and the start of the $21^{\text {st }}$ century, the problem of increasing students' self-esteem required an urgent solution. The rapidly developing information society has faced the challenge of developing a person who can independently orient him/herself in different situations, manage not only him/herself but also the cognitive activity of his/her surroundings, separate the nature of information flows, and select evidence-based information to build effective interactions with the environment for the sake of a more developed society.

In various historical periods, the theory and practice of pedagogy have shown that the key role of education has been given to one of the two sides of the teaching and learning process: (1) pedagogue (teacher, lecturer, and trainer) or (2) learner (student, pupil). The point of view gets much more interesting when the learner or the student is the future teacher, and pre-service teacher education is organized at universities. Teacher education is a comprehensive process in which every element should be taken into consideration.

From this aspect, the scope of the learning process is expanding, and the learning process can no longer be satisfied with the transfer of knowledge and formulation of skills and abilities by multiple repetitions of that knowledge with their simple mindset. Here, the wide scope of the professional competences of a teacher is noticed. In the complex of the professional competences of a teacher, the following main competences are highlighted: general (knowledge in the framework of pedagogy or on certain subjects, research, culture, etc.), social (interaction skills, socialisation skills, etc.), subject-related competences (teaching methodology frameworks, implementation of subject-related research, etc.) and empirical-practical competences (skills and abilities to make possible the outcomes of the teaching subject, practical experience in the field, and practical techniques that help to apply key functions as a teacher, such as forecasting learning outcomes, studying learners' abilities to learn the subject, problem diagnostics and solving, interaction with learners, educational counseling, educating, 
development of the learner's personality, facilitating learning, orientation of a student to self-development, etc.).

How these specific competences are shaped and which competences are dominant are determined by competent approaches to the education process and by mechanisms of competent approaches. The formation of a competent approach was initially determined by education innovations. The bases of competent approaches are found in the United States and developed European countries, and their scientific foundations are related to the theory of John Dewey. This approach found its practical formulation and application in the 1997 UNESCO report, having come to prominence and entered into action.

\section{Methodological Bases of Competence Development and Hybrid Pedagogy/Blended Teaching and Learning}

It is necessary to formulate clear concepts of competences, since they are extremely practical in nature and determine both the effectiveness of education and the formation of future specialists, especially future teachers, since the final result of the entire education system, the quality of education, depends on their work. That is why, when we talk about improving the competence of a teacher, we understand that this is directly proportional to improving the quality of education. On the other hand, the formation of competences is included in the quality education and qualifications of a specialist.

\section{Qualification - "Quality" Competence - Teacher - Educational process - - Result - Quality-Qualification - "Quality" Competence}

Each "quality" competence has the following structure:

1. content (knowledge, abilities, skills);

2. activity (practice, experience);

3. process context (case-related);

4. methodology (methods, techniques);

5. social (interaction, collaboration, socialisation in education with specific groups of learners, colleagues, etc.);

6. self-regulation (self-development, self-analysis, self-criticism, self-evaluation etc.). 
The methodological concepts of J. Dewey (1938), B. Bloom et al. (1956), D.A. Schön (2017), J. Bruner (Constructivist Theory), C. Rodgers (2002a, 2002b), etc. have shown the importance of the development of teachers' professional competences.

It is very interesting to discuss the professional competences of a teacher in the framework of the concepts generated by the modern theory of teaching, which is constructed by hybrid pedagogy. Hybrid pedagogy creates modern approaches to the organisation of education processes, combining the above-mentioned theories and modern challenges of e-learning concepts, based on the catalyst framework of the education process, and it revises Bloom's taxonomy.

Figure 1. Catalyst framework of the education process

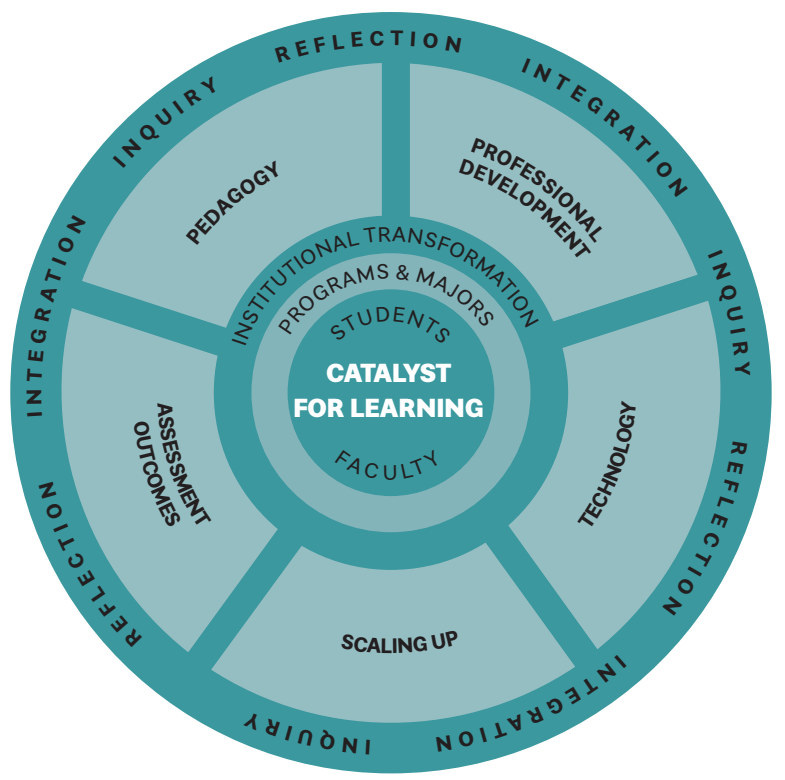

Source: Catalyst for Learning, n.d.

\section{Engaged Learning in Modern Education}

In the second half of the $20^{\text {th }}$ century, new problems were raised in the field of education related to increasing the degree of independence of students and the independent acquisition of knowledge by students. Independent learning is when pupils set goals and monitor and evaluate 
their own academic development so they can manage their own motivation towards learning. The rapidly developing information society formulates the problem of the development of a personality, solved by educational processes, and that personality can be independently guided in various situations and manage the cognitive activities of not only itself but also those of people around it and its environment, distinguish between the essence of information flows and choose provable information, and create effective interactions with the environment for the sake of a more developed society.

From this point of view, the scope of the problems of the educational process expanded, and the modern educational process could no longer be satisfied only with the transfer of knowledge and the ability to formulate skills in multiple repetitions of this knowledge with simple thinking. Moreover, this function was somewhat taken up by computer hardware.

Within the context of contemporary education, Bloom presents ways of implementing innovative learning in his well-known taxonomy that guides educational specialists. In accordance with Bloom's taxonomy (Bloom et al., 1956) of the goals, stages and organisation of the learning process, the cognitive process includes the following key stages:

1. Knowledge: to remember, distinguish, and find information in the form of facts, rules, formulas, figures, definitions, etc.

2. Comprehension: verbal explanations, generalisation, examples, interpretation.

3. Application: the application of information during a specific operation.

4. Analysis: to identify the relationship between the structural components of information.

5. Synthesis: to obtain information from other sources based on existing knowledge.

6. Evaluation: judgments and choice of criteria, as well as the ability to evaluate various pieces of evidence and realities.

New tasks were supplemented by the already-formed traditional issues of learning. The introduction of innovative forms of learning does not imply a denial of traditional, successful experience. "Innovative" or "creative" learning does not replace traditional learning but 
supplements it and makes it more relevant to modern requirements and problems.

Contemporary pedagogical theory and practice are designed to identify ways of maximising a learner's active engagement in the process of learning so that he/she can quickly find a way to learn and learn independently and to form their own opinions and new approaches that will lead to creativity and new knowledge. One of the main reasons for that is that the innovative paradigm of education, on which the modern education system is based, is called "personality-oriented".

In modern textbooks on pedagogy, three objectives of the traditional learning process are knowledge and the formation of skills and abilities; in addition, there are two more objectives of the modern educational process - to learn how to learn and to create new knowledge.

Figure 2. Current objectives of the learning process

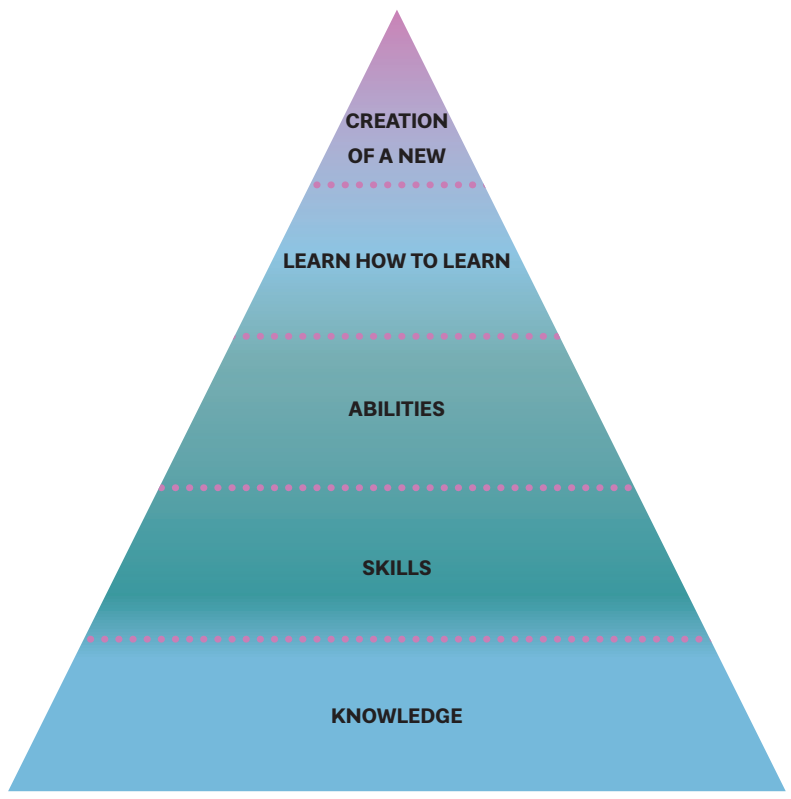

In summary, it is important to note that in the current learning process, a significant role is played by both the teacher and the learner. And only the realisation of the role of each and the scope of the function of this role can provide a training process that meets modern requirements and successful results. 
Figure 3. Bloom's taxonomy of hybrid pedagogy

\section{BLOOMS TAXONOMY}

TRADITIONAL

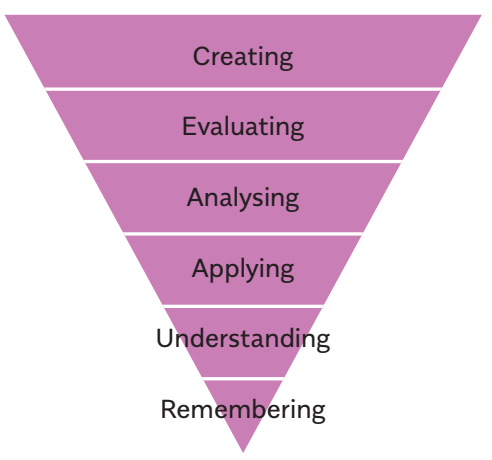

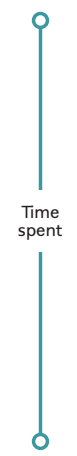

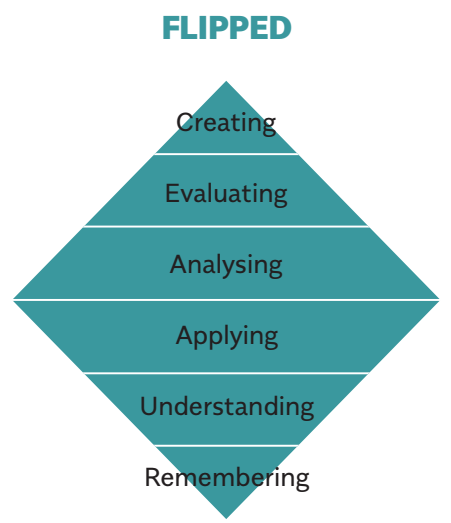

"Hybrid/blended teaching and learning" is consistently being increasingly used to describe how e-learning/e-teaching/self-learning methods are used in a mixed way with traditional classroom methods. This has contributed to the creation of new educational technologies in teaching methods. It also represents a fundamental change in the traditional teaching and learning experience offered by teachers and learners.

Hybrid pedagogy is a broader phenomenon than just the use of "traditional" computers and multimedia methods. A wide range of approaches is also available along with the technological infrastructure. The pedagogical aspects will naturally consider the specific aspects of learning so that learners can work in groups and present their final work. The idea is to make learners more active, improve the quality of instruction, and inspire them to develop new tools and new materials.

\section{Reflective Teaching and Modern Learners in the Framework of the Constructivist Learning Approach}

The constructivist learning approach states that the learner takes an active role in constructing their own understanding rather than receiving it from someone who knows. Learners interpret information from the unique personal perspective of their previous experience. Information has to be personalized into knowledge. 
Constructivism is "an approach to learning that holds that people actively construct or make their own knowledge and that reality is determined by the experiences of the learner" (Elliott et al., 2000, p. 256).

The methodological bases of the constructivist learning approach belong to the theories of J. Piaget, L. Vigotsky, J. Bruner, M. Montessori, J. Dewey, K. Rogers and others. J. Dewey has played a specific role in this regard by writing his famous book Experience and Education (Dewey, 1938).

A constructivist learning approach explains the role played by experience during learning, even during each class and lesson, highlighting reflection as the main learning activity that makes it possible to construct experience. The learning activities in this regard are observation, selection, transformation, processing, interpretation, integration, choice-making, discovery, dialogue, interaction, contextualisation, and reflection. In order to understand the reality of the construction experience and reflection during teaching and learning, we have to look at Rodger's Reflective Cycle (Figure 4).

Figure 4. Rodger's Reflective Cycle

Presence in Experience Learning to see

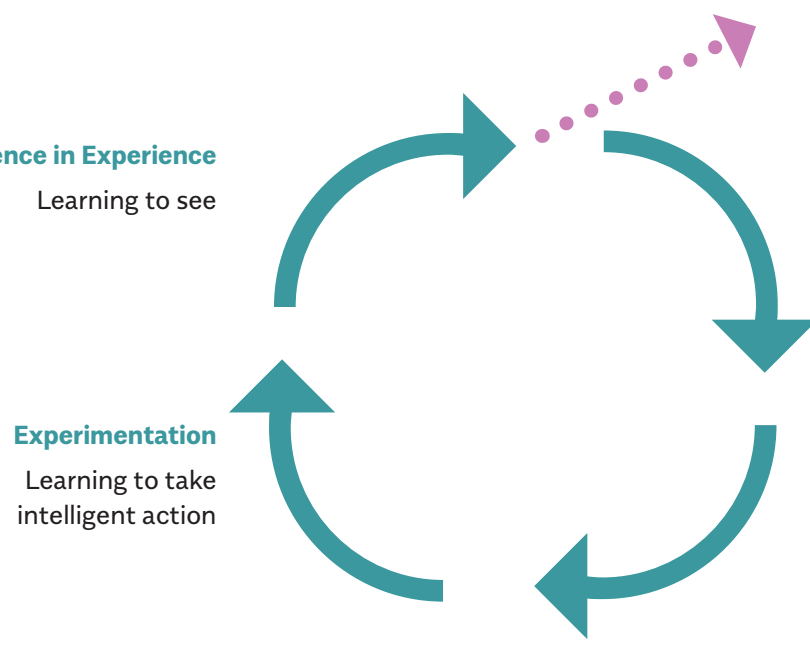

Description of Experience Learning to describe and differentiate

Analysis of Experience Learning to think from multiple perspectives and form multiple explanations

Source: Rodger, 2020, p. 235.

"This confluence of experiences (action) and thought (reflection) combines to create new knowledge... Reflection then is the vehicle for critical analysis, problem-solving, synthesis of opposing ideas, 
evaluation, identifying patterns, and creating meaning - in short, many of the higher order thinking skills we strive to foster in our students" (Burns, Dimock \& Martinez, 2000).

The role of experience in the formation of professional competences and reflection was emphasized so much that the teacher has been called a "reflective practitioner" (Schön, 2017). In this understanding, the reflective practitioner teacher has to:

1. frame and reframe a problem;

2. test their own interpretations, values and beliefs and modify their own actions as a result;

3. rely less on theory than on the kind of improvisation learnt in practice to meet the challenges of their work;

4. center their professional education on enhancing their self-reflection;

5. reflect-on-action and reflect-in-action.

From this aspect, the teacher has a new role and learning activities have new content. The teacher has to be not only a facilitator but also a reflective practitioner, which is about creating and providing space for learners to:

1. try out or create something new,

2. reflect on their own experiences,

3. arrive at new conclusions, and

4. think about how they would apply these conclusions in their work and life.

In this view, learners get more motivation for their self-actualisation and self-development with orientation and help from their teacher.

But a question then arises: How is it possible to define learning activities according to reflective teaching that ensure the engagement and motivation of the learners?

In hybrid pedagogy, a wide range of activities and e-tivities are worked out, the use of which makes it possible for the teacher to overcome modern challenges and get the required outcomes in the learning process. The peculiarities of e-tivities are explored by Gilly Salmon, who explains the different specifications of e-learning tools in educational actions (Figure 5). 


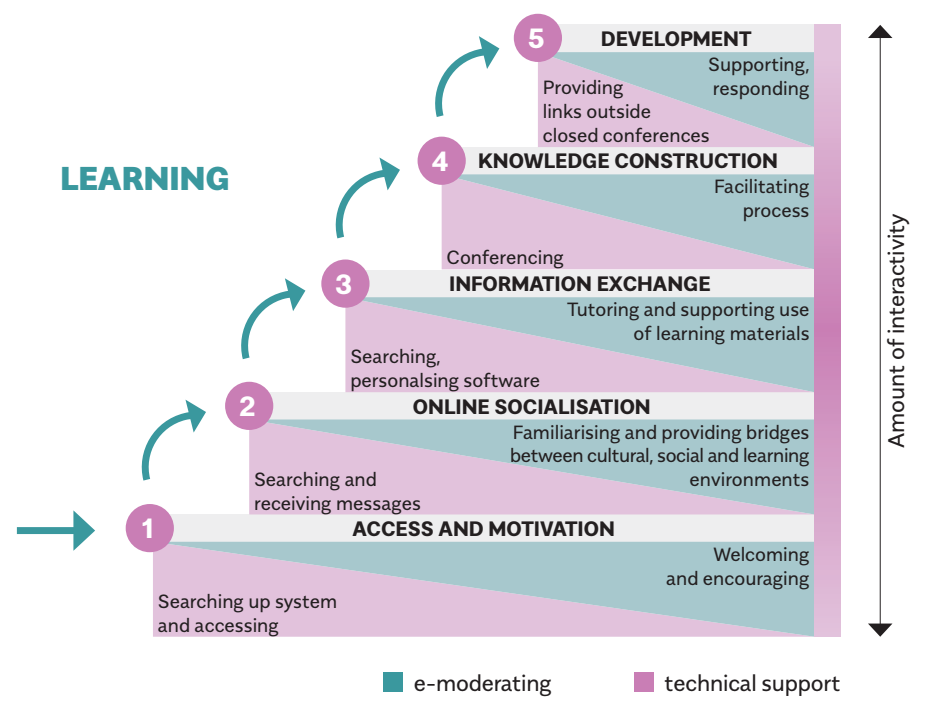

Resources and further explanation: www.gillysalmon.com/five-stage-model.html.

These activities and e-tivities are oriented at the motivation, reflection, and construction of experience, which promotes the creation of new knowledge by students. There are different e-tivities that have been practiced and are well-known as being effective, for example, the e-portfolio. E-tivities have certain elements, which are the definition of their purpose, the presentation of the task, and interaction.

The purposes of e-tivities are to:

1. increase learner engagement,

2. save staff time,

3. make the course productive and fun,

4. easily deploy newer technologies such as social media,

5. easily find purposeful ways of using freely available, topical and/ or fun resources within the learning design, and

6. incorporate sound pedagogical principles quickly into teaching and learning. 
The teacher as a reflective practitioner became an e-moderator. An e-moderator has to interact and intervene in the following ways: be present, support, monitor activity, facilitate, ask questions, summarize, provide orientation, point students into new directions, give feedback, etc.

\section{Conclusion}

Modern quality education is not possible without information technologies and online learning tools. Hybrid pedagogy blends teaching and learning activities with e-tivities, engaging them in learning processes aimed at self-reflection and getting experience.

There should be a teaching idea, i.e. an idea that should shape a teaching culture, and the teaching culture of each teacher should in turn create a culture of teaching and learning in an educational institution. It is important here that the scale of teaching is guaranteed to ensure efficiency for the success of the whole. The concept of discipline is very important here, especially from the perspective that each teacher should have an understanding of what scale of education he or she wants to invest in - the success of a particular lesson, a topic, a course, the whole educational programme or the whole institution. This is important in terms of what the teacher identifies him/herself with in terms of short-term goals, mid-term outcomes, or long-term success. That is, does the teacher want to change something in the educational culture of the institution? It does not matter here whether the teacher performs induction or deduction; the most important thing is that he/she sees him/herself in all teaching processes as a reflective practitioner.

And for all these above-mentioned points, in the framework of pre-service teacher education at universities, the following is needed:

1. a pedagogical theory in order to understand all aspects of teaching, especially didactics;

2. technological saturation;

3. professional development - universities must ensure the development of professionals involved in local and international teaching experience aspects;

4. an adequate evaluation of the results, including the opinions of the learners and the results of the students' self-assessment, i.e. whether the learner has also realised what has changed in the structure of his/her professional knowledge and competences. 
Speaking about modern innovative teaching technologies over the past decade, it should be borne in mind that the third decade of the $21^{\text {st }}$ century is aimed at making learning oriented on the expectation of active feedback from students, and not on the expectation of their spontaneous participation in each stage of the learning process. Consequently, the most important result is the formation of their experience through reflection and engaged teaching and learning.

\section{References}

$\rightarrow$ Bloom, B.S., Engelhart, M.D., Furst, E.J., Hill, W.H. and Krathwohl, D.R. (1956). Taxonomy of educational objectives: The classification of educational goals. Handbook I: Cognitive domain. New York: David McKay.

$\rightarrow$ Burns, M., Dimock, M. and Martinez, D. (2000). Action + Reflection = Learning, TAP Into Learning, 3(2).

$\rightarrow$ Catalyst for Learning. http://c2l.menrc.org

$\rightarrow$ Dewey, J. (1938). Experience and Education. New York: Simon \& Schuster.

$\rightarrow$ Elliott, S.N, Kratochwill, T.R and Littlefield Cook, J. (2000). Educational Psychology: Effective teaching, Effective learning. Boston: McGraw Hill.

$\rightarrow$ Rodgers, C. (2002). Defining Reflection: Another Look at John Dewey and Reflective Thinking, Teachers College Record, 104(4), 842-866.

$\rightarrow$ Rodgers, C. (2002). Voices inside schools seeing student learning: Teacher change and the role of reflection, Harvard Educational Review, 72(2), 230-253.

$\rightarrow$ Salmon, G. (2004). E-moderating. The Key to Online Teaching and Learning ( $3^{\text {rd }}$ ed.). London: Routledge.

$\rightarrow$ Salmon, G. (2013). E-tivities: The key to active online learning. London: Routledge.

$\rightarrow$ Salmon, G. (n.d.). The Five Stage Model. www.gillysalmon.com/five-stagemodel.html

$\rightarrow$ Schön, D.A. (2017). The reflective practitioner: How professionals think in action. London: Routledge. 